\title{
Exergames for health and fitness: the roles of GPS and geosocial apps
}

\author{
Maged N Kamel Boulos ${ }^{1 *}$ and Stephen P Yang ${ }^{2}$
}

\begin{abstract}
Large numbers of children and adolescents in Canada, UK and USA are not getting their recommended daily dose of moderate to vigorous physical activity, and are thus more prone to obesity and its ill health effects. Exergames (video games that require physical activity to play) are rapidly gaining user acceptance, and may have the potential to increase physical activity levels among young people. Mobile exergames for GPS (global positioning system)enabled smartphones and mini-tablets take players outdoors, in the open air, unlike console exergames, e.g., Xbox 360 Kinect exergames, which limit players to playing indoors in front of a TV set. In this paper and its companion 'Additional file 1', we review different examples of GPS exergames and of gamified geosocial apps and gadgets (mobile, location-aware apps and devices with social and gamification features), and briefly discuss some of the issues surrounding their use. Further research is needed to document best practices in this area, quantify the exact health and fitness benefits of GPS exergames and apps (under different settings and scenarios), and find out what is needed to improve them and the best ways to promote their adoption by the public.
\end{abstract}

Keywords: GPS (global positioning system), Geosocial apps, Location-based games, Exergames, Physical activity, Smartphones

\section{Background}

Current guidelines for physical activity recommend that children and young people accumulate at least 60 minutes of moderate to vigorous physical activity (MVPA) daily. Unfortunately, very many children and adolescents aged 5-18 in Canada, UK and USA are not getting their recommended daily dose of MVPA [1-3], and are thus more prone to obesity and its ill health effects. Furthermore, research shows that children and adolescents are increasingly spending more time being sedentary while consuming various types of electronic and online media [4]. Physical inactivity (often associated with poor diet and overweight) has been blamed as one of the leading causes of death in the United States [5].

The problem is that, other than organised sports, there are not many enjoyable alternatives to obtain MVPA. However, exergames (video games that require physical activity or moving one's body to play [6]) and GPS (global positioning system) exergames (electronic, location-based games that are played outdoors with the help of GPS in mobile

\footnotetext{
*Correspondence: mnkamelboulos@plymouth.ac.uk

'University of Plymouth, Drake Circus, Plymouth, Devon PL4 8AA, UK

Full list of author information is available at the end of the article
}

devices carried by players) are rapidly gaining acceptance, and may have the potential to increase physical activity levels among young people.

Children and adolescents like playing video games [4]; but until recently, many did not see the use of video games as being beneficial in promoting physical activity. Challenging that belief is a group of newer console video games and controllers such as the Xbox Kinect [6,7], that allow players to physically interact with the game and burn more calories in the process (exergames). However, the biggest limitation of console exergames is that they require a television set or computer monitor to play, and cannot be played outdoors on a mobile device.

The adoption rate of smartphones has "exploded" in recent years and is said to be growing faster than that of any other consumer technology in history [8,9]. Among the most popular categories of smartphone apps are those dealing with health and fitness, exercise routines and dietary food intake, as well as social apps and games. Many smartphones and mini-tablets also incorporate GPS [10], and apps are now available that have capitalised on GPS and 'network location' functionalities in mobile devices, and incorporated game mechanics or gamification features that

Ciomed Central 
engage the user beyond the basic GPS functions of location, elevation, time, distance and speed, e.g., in alternate-reality games (ARG) and in other types of location-based exergames that require players to move and perform game tasks in a specific geographical area or in a non-pre-defined area. In this paper, only those mobile apps that have "advanced" GPS functions and game mechanics will be considered.

\section{Survey of GPS exergames and gamified geosocial apps and gadgets}

We conducted an extensive online search of existing product literature about GPS exergames and geosocial apps and gadgets. We also scanned the most popular online mobile stores/marketplaces (e.g., Google Play [11]) for such apps. Our results are presented in 'Additional file 1'. They cover: (i) mobile, location-based game apps, e.g., Dokobots (Figure 1); (ii) mobile, location-aware fitness and sports hubs/platforms with social and gamification features, e.g., EpicMix ski app (Figure 2) and Microsoft HealthVault (Figure 3); and (iii) location-aware sports gadgets, e.g., Oakley Airwave GPS-enabled Goggle for skiing (Figure 4) and products combining GPS and heart rate monitoring of the player.

\section{Discussion}

Smartphone and GPS technologies are already playing important roles in telehealthcare and in medical emergencies [12-14], but here we are presenting some additional, non- conventional (in the context of health and healthcare) uses of these technologies, which can help keep our populations healthy and fit through the use of GPS in interesting and motivating outdoor games.

\section{Central themes of location-based exergames, game maps and user customisation options}

The exergames presented in 'Additional file 1' cover a range of themes, including geocaching, (virtual) treasure hunting and item collection, trying to beat opponents and rank highest on leaderboards in multiplayer games, and games fashioned around visiting new locations, as in geodashing, geohashing, waymarking, etc. The latter group of exergames may also offer an educational opportunity to discover new places and learn about their geography and environment.

Bunker Buster [15], one of the geosocial games in our survey, uses Foursquare [16] venues as the game board. According to a study by the Pew Internet \& American Life Project published in 2012, 18\% of US smartphone owners over 18 used geosocial check-in apps such as Foursquare to "check in" to different locations and/or share their location with friends [17].

In location-based exergames, game maps (or playgrounds) are existing areas and streets in the real world outdoors. These maps and any associated virtual (or real) items on them, which players are supposed to avoid or find/collect or interact with in some other way, can be auto-generated (by the game engine/server) and/or user-

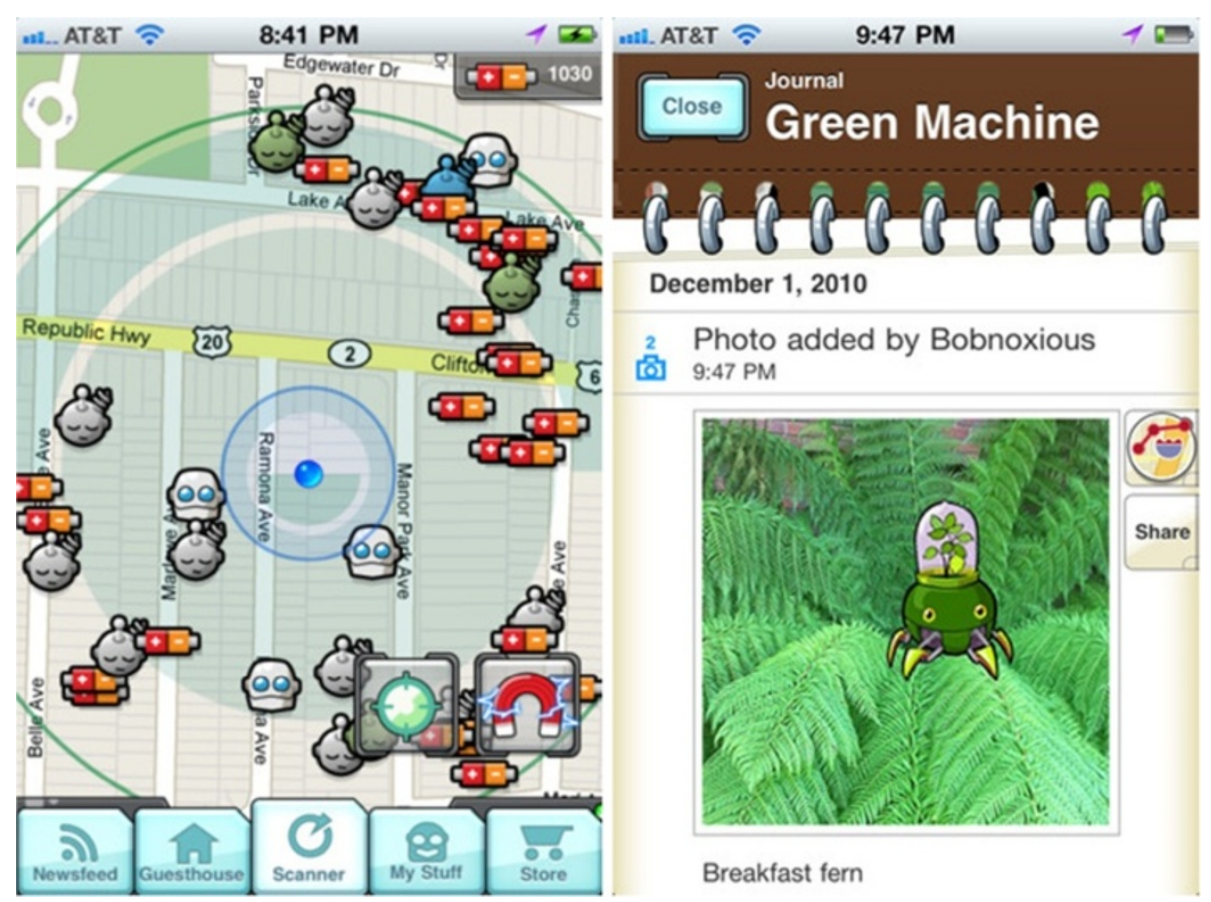

Figure 1 Dokobots exergame for the iPhone/iPod touch/iPad. Please refer to 'Additional file 1' for a detailed description of this product. 


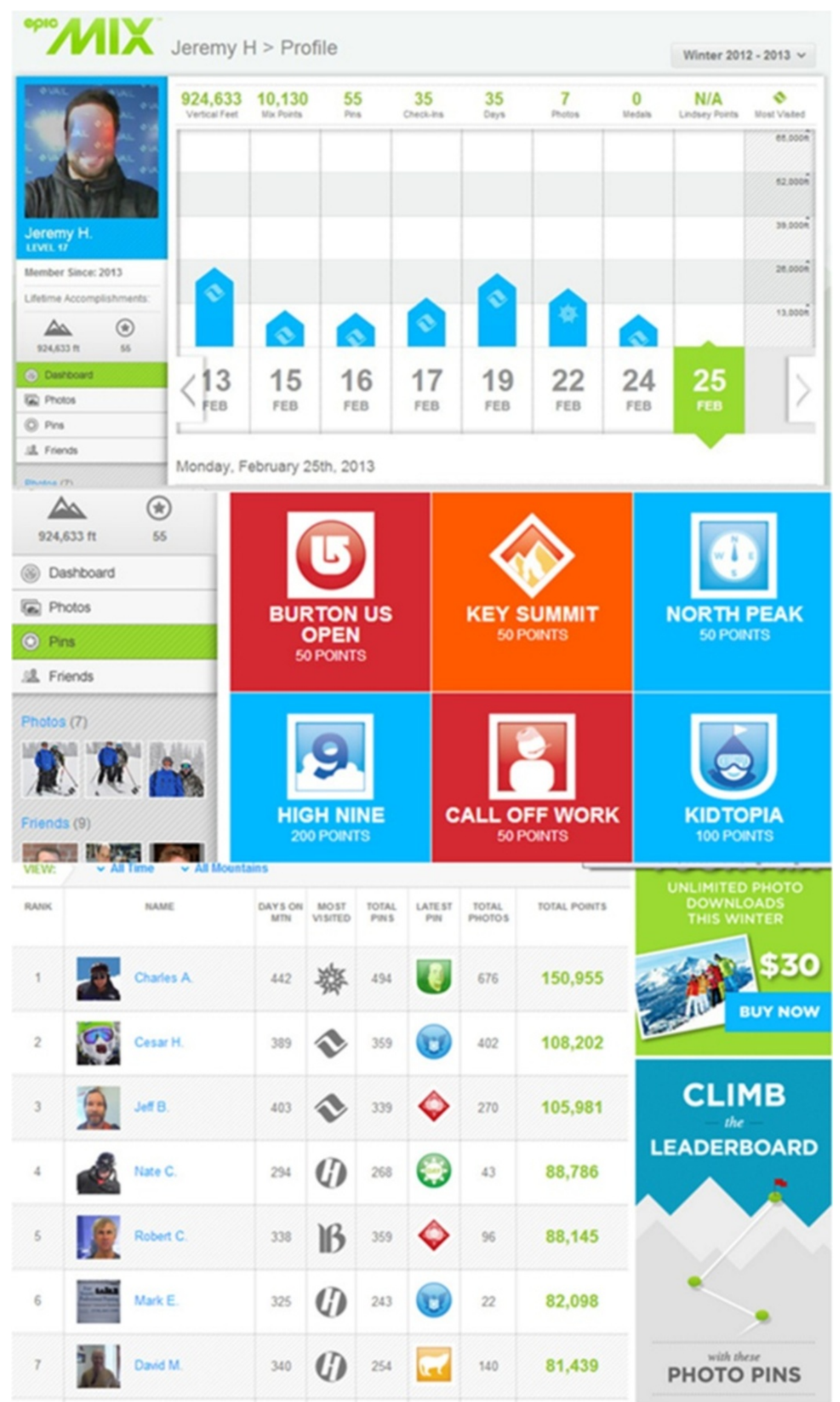

Figure 2 Gamification features in EpicMix at Vail Resorts: pins (achievements) and leaderboards. The geolocation technology used in EpicMix is RFID (radio-frequency identification) rather than GPS. Please refer to 'Additional file 1 ' for a detailed description of this product. 


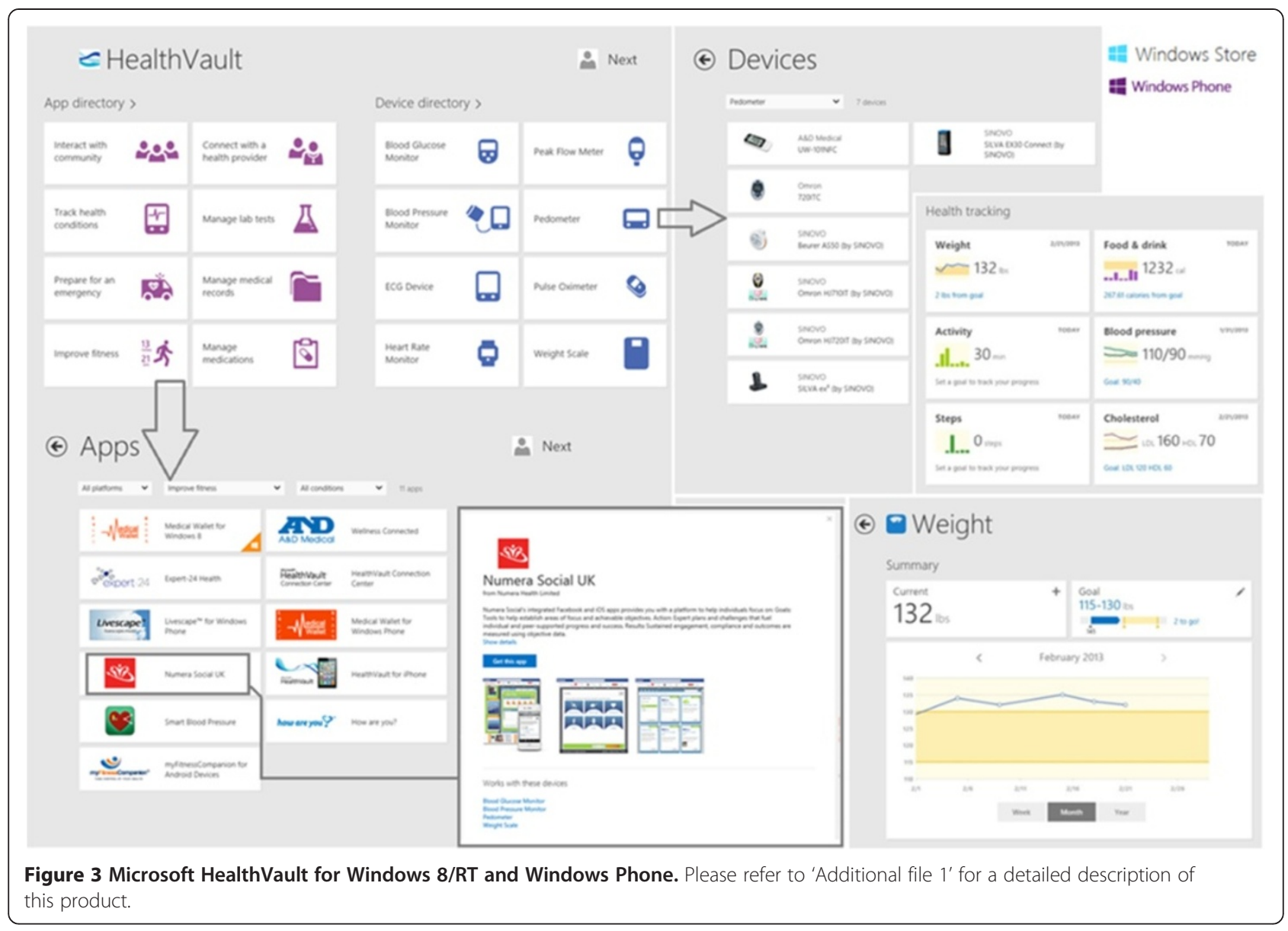

generated (in those games that offer the option for players to create their own game maps). A good example of the latter is the Mission Designer mode of GPS Mission Pro (a GPS exergame), where anyone can create new missions for whatever location they have decided to use, and add game elements such as clues, photo tasks and bonus items [18].

Another example of user customisation and usergenerated content offered by products in our survey is MovesCount App Zone, Suunto's Ambit GPS watches companion app community and apps [19]. These sports apps, although not proper games as such, enable users to customise their GPS watches and to interactively define the parameters of their workout without any programming tools or knowledge. Using Suunto's App Designer, users can even create (and share) their own apps, if they cannot find an existing app that satisfies their requirements.

\section{Shortcomings of GPS exergames}

GPS technology issues are well documented elsewhere, e.g., in [12], and include location privacy issues and the GPS receivers sometimes failing to find a 'fix', e.g., when operating in some urban canyons, in heavy foliage environments, or in covered places, such as inside a large shopping mall or underground train station.

Although conquering new lands and getting new items is exciting no matter whom the player is battling or what he/ she needs to collect, the biggest risk of auto-generated tokens, awards and enemies in GPS exergames is the safety of the game player. Players of GPS exergames can find themselves wandering in hazardous or prohibited/private areas if they do not exert due caution. The game might place an award in a dangerous location or it may be inaccessible by foot, and these compromising positions are a risk. In 2011, a mysterious object (black box) used in a GPS-based treasure hunt game caused a scare and resulted in parts of the Downtown Disney Park in Anaheim, CA, USA, to be temporarily closed down for a short time by the bomb squad [20].

GPS exergames, like other smartphone apps, can also be a potential source of malware [21], and users should only download and install apps from trusted sources, paying particular attention to the permissions they grant to each app.

Apps should ideally establish and adjust to individual players' fitness profiles, warning users against playing for prolonged periods of time without taking enough rest (and 


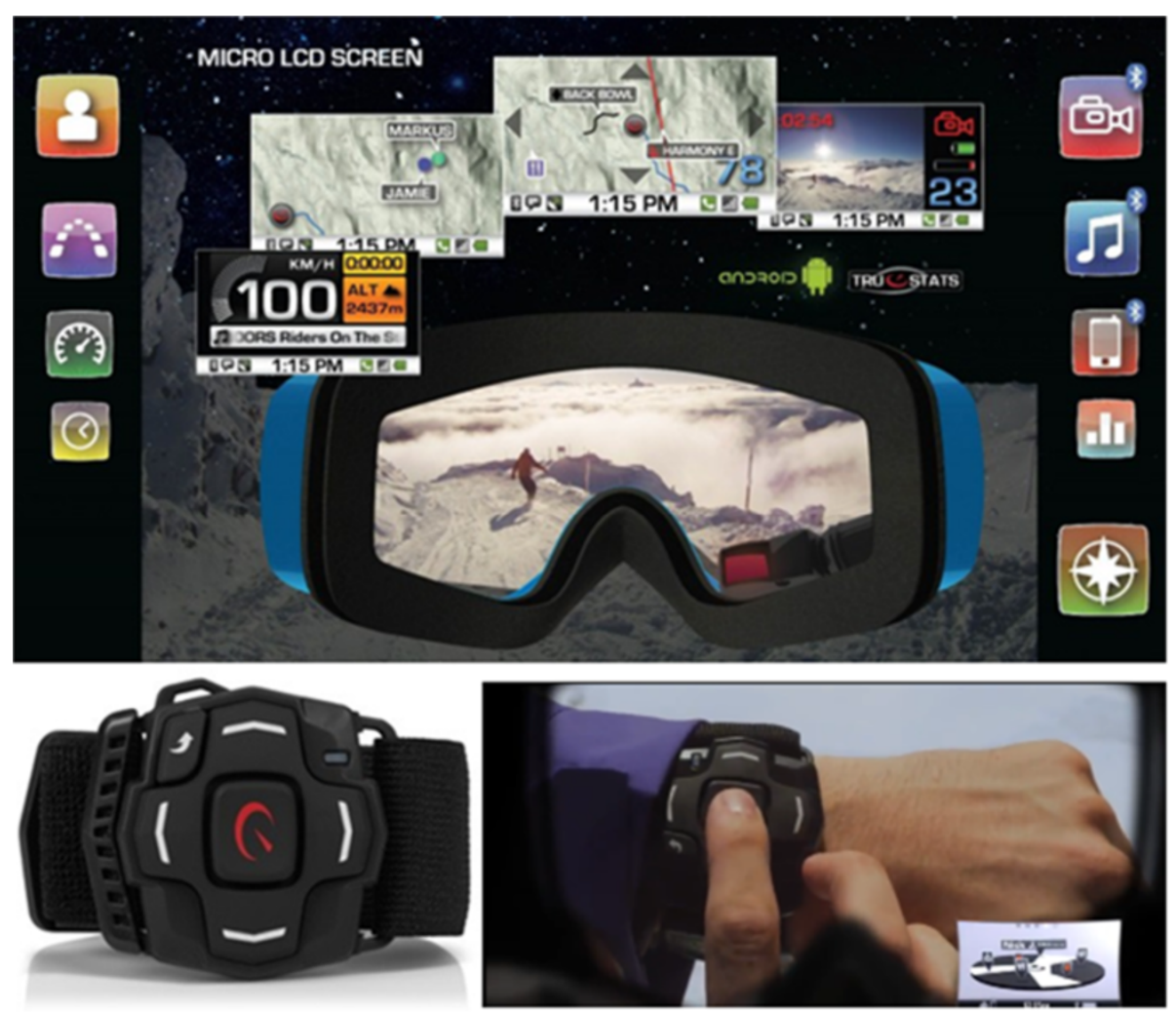

Figure 4 Oakley GPS Goggle. Please refer to 'Additional file 1' for a detailed description of this product.

hydration) and against engaging in dangerous exercise levels, particularly for those players with some pre-existing health condition, e.g., heart disease or type I diabetes (hypoglycaemia risk), or players with overall low fitness levels (when heavy exercise they are not previously accustomed to is suddenly introduced).

\section{The social/multiplayer effect}

Many of the mobile exergames listed in 'Additional file 1 ' feature a prominent social or multiplayer component. In a recent study about console exergames, O'Donovan et al. found that playing the games in multiplayer mode led to greater energy expenditure and heart rate than playing in single player mode [22]. The same 'multiplayer effect' can be rather safely assumed to apply to mobile GPS exergames, but research is still needed to confirm (and quantify) this effect in outdoor settings.

\section{An SDT (self-determination theory)-based framework for future research}

To further improve location-based exergames and their uptake, more research is warranted and should focus on what youngsters like to do. Researchers should investigate games and activities that youngsters are already intrinsically motivated to play. The foundations for self-determination theory (SDT) can help parents, educators and exergame designers foster environments that develop self-determined motivation. To examine youngsters' motives for participating in games they enjoy, the framework in Figure 5 was adapted from previous research on SDT and socialcognitive theory [23-25].

This framework suggests that individuals may have motives to participate in an activity, which may include enjoyment or physical appearance/weight loss. An example would be a girl who uses Nike + GPS Tag [26] to have fun and exercise. The motives to play Nike + GPS Tag feed into the mediators of the activity, which include competence, autonomy and relatedness. If the girl thinks that by playing Nike + GPS Tag she will feel competent, she will likely continue playing. Continued feelings of competence would likely lead to self-determined (intrinsically motivated) behaviour. Some of the outcomes from playing Nike + GPS Tag might include physical activity, enjoyment and adherence. Most of the available literature on SDT does not use a representational model like the one adapted in Figure 5. From a practical viewpoint, 


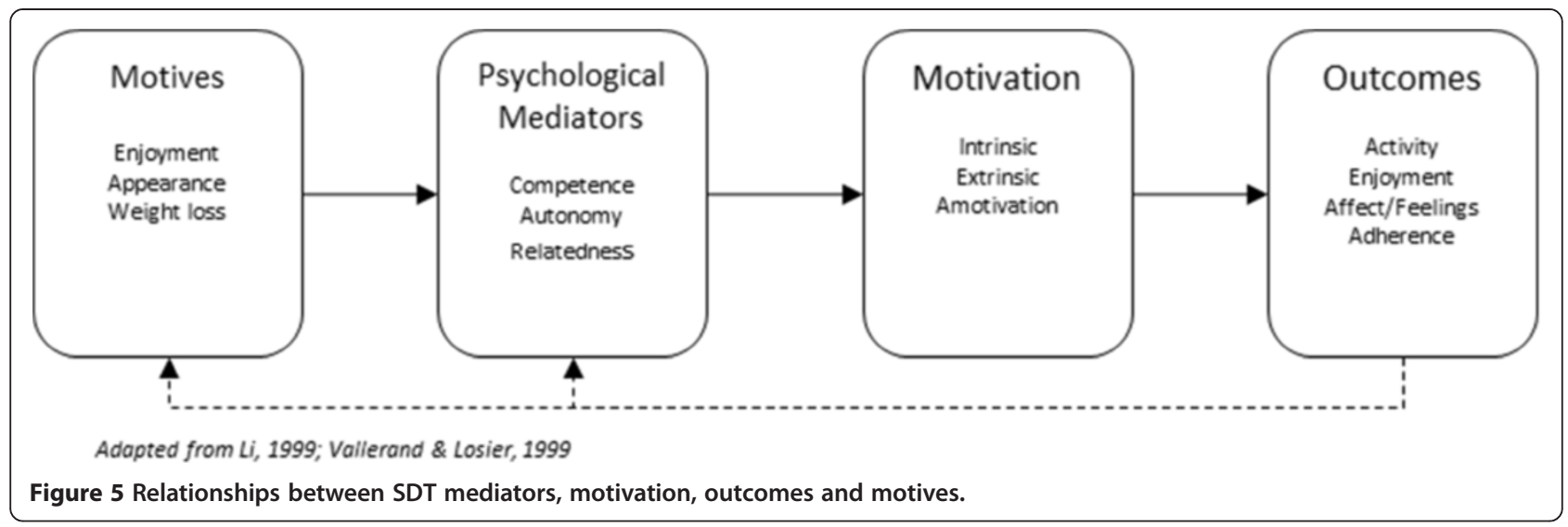

there should be some form of feedback from the experience of playing a game. In Figure 5, the feedback (arrows) from the outcomes, flow back into the motives and mediators. It makes more sense for the relationships to be cyclical as opposed to linear.

Parents, educators and community leaders need to foster socially supportive and fun environments for positive youth development. Research has shown that young people learn best when they are interested and engaged. Youngsters feel motivated when they are with their peers in voluntary settings, such as sports and hobbies. Youngsters then have a 'window of opportunity' to engage in activities in which they freely chose to participate. By empowering youngsters to choose for themselves, sports and physical activity (including activity arising from playing exergames) can provide unique environments that help build competence, autonomy and relatedness. Studies indicate that participation in voluntary structured activities during non-school time is associated with the development of positive identity, increased initiative and positive relationships with diverse peers and adults, better school achievement, reduced rates of dropping out of school, reduced delinquency and more positive outcomes in adulthood [27]. Location-based exergames that are played outdoors can potentially play an important role in all these aspects of youth development.

\section{Conclusion}

Location-based exergames are here to stay. While many would prefer to see young people obtaining their physical activity through sports, it seems increasingly clear that for some youngsters growing up in the 21st century, GPS exergames may be a popular alternative (or supplement) to conventional sports such as football and skiing. Some of the apps and gadgets surveyed in this paper, such as EpicMix ski app, add additional dimensions to conventional sports. If GPS exergames can be as motivating to play as traditional video games, and they have the additional physical activity benefits, we should continue to research, explore and encourage their use. The 'Game ON (Outdoor Nation)! Challenge Grants' seem a good step in this direction [28]. Individuals and teams, beginners and experts alike, are invited to create a new app or mobile game, or promote an existing game, to inspire youth to get outdoors and active. Grants of US $\$ 5,000$ will be given to the top four projects and the winners will also have the opportunity to attend the E3 video game conference and show in Los Angeles in June 2013.

\section{Additional file}

Additional file 1: List of GPS exergames and geosocial apps and devices. PDF (Portable Document Format) document listing a large number of GPS exergames and geosocial apps/devices arranged in alphabetical order by game/app/gadget name, with short descriptions and Internet links.

Competing interests

The authors declare that they have no competing interests.

Authors' contributions

MNKB conceived the manuscript's idea and drafted the paper and companion 'Additional file 1', with professional physical education insight and contributions from SPY (ExerGame Lab). Both authors read and approved the final manuscript.

\section{Acknowledgements}

Commercial products and company/brand names mentioned in this paper and the companion 'Additional file 1' are trademarks and/or registered trademarks of their respective owners.

\section{Author details}

${ }^{1}$ University of Plymouth, Drake Circus, Plymouth, Devon PL4 8AA, UK. ${ }^{2}$ SUNY Cortland, Cortland, NY 13045, USA.

Received: 17 March 2013 Accepted: 24 March 2013

Published: 5 April 2013 


\section{References}

1. Physical activity levels of Canadian children and youth, 2007 to 2009. http:// www.statcan.gc.ca/pub/82-625-x/2011001/article/11553-eng.htm.

2. Chief Medical Officers of England, Scotland, Wales, and Northern Ireland: Start Active, Stay Active: A report on physical activity for health from the four home countries' Chief Medical Officers. London: Department of Health, Physical Activity, Health Improvement and Protection; 2011. http://www.dh. gov.uk/prod_consum_dh/groups/dh_digitalassets/documents/digitalasset/ dh_128210.pdf.

3. Nader PR, Bradley RH, Houts RM, McRitchie SL, O'Brien M: Moderate-tovigorous physical activity from ages 9 to 15 years. JAMA 2008, 300(3): 295-305. doi:10.1001/jama.300.3.295.

4. Rideout VJ, Foehr UG, Roberts DF: Generation M2: media in the lives of 8- to 18-year-olds. Menlo Park, CA: Kaiser Family Foundation; 2010. http://www.kff. org/entmedia/upload/8010.pdf.

5. Mokdad AH, Marks JS, Stroup DF, Gerberding JL: Actual causes of death in the United States, 2000. JAMA 2004, 291(10):1238-1245. doi:10.1001/ jama.291.10.1238.

6. Kamel Boulos MN: Xbox 360 Kinect exergames for health. Games for Health Journal: Research, Development, and Clinical Applications 2012, 1(5): 326-330. doi:10.1089/g4h.2012.0041

7. Kamel Boulos MN, Blanchard BJ, Walker C, Montero J, Tripathy A, Gutierrez-Osuna R: Web GIS in practice X: a Microsoft Kinect natural user interface for Google Earth navigation. Int J Health Geogr 2011, 10:45. doi:10.1186/1476-072X-10-45.

8. IOS and Android Adoption Explodes Internationally. http://blog.flurry.com/bid/ 88867/iOS-and-Android-Adoption-Explodes-Internationally.

9. EU5 Smartphone Penetration Reaches 55 Percent in October 2012. http://www comscore.com/Insights/Press_Releases/2012/12/

EU5_Smartphone_Penetration_Reaches_55_Percent_in_October_2012.

10. Four Out of Five Cell Phones to Integrate GPS by End of 2011. http://www. isuppli.com/Mobile-and-Wireless-Communications/News/Pages/Four-out-ofFive-Cell-Phones-to-Integrate-GPS-by-End-of-2011.aspx.

11. Google Play. http://play.google.com.

12. Kamel Boulos MN, Rocha A, Martins A, Escriche Vicente M, Bolz A, Feld R, Tchoudovski I, Braecklein M, Nelson J, O Laighin G, Sdogati C, Cesaroni F, Antomarini M, Jobes A, Kinirons M: CAALYX: a new generation of locationbased services in healthcare. Int J Health Geogr 2007, 6:9. doi:10.1186/ 1476-072X-6-9.

13. Kamel Boulos MN, Wheeler S, Tavares $C$, Jones R: How smartphones are changing the face of mobile and participatory healthcare: an overview, with example from eCAALYX. Biomed Eng Online 2011, 10:24. doi:10.1186/ 1475-925X-10-24

14. Kamel Boulos MN, Anastasiou A, Bekiaris E, Panou M: Geo-enabled technologies for independent living: examples from four European projects. Technol Disabil 2011, 23(1):7-17. doi:10.3233/TAD-2011-0300.

15. Bunker Buster. https://play.google.com/store/apps/details?id=com. projectzebra.bunkerbuster.

16. Foursquare. https://foursquare.com.

17. Three-quarters of smartphone owners use location-based services. http:// pewinternet.org/Reports/2012/Location-based-services.aspx.

18. GPS Mission Pro Mission Designer. http://gpsmission.com/missionadmin/create.do.

19. Suunto's MovesCount App Zone and App Designer. http://www.movescount. com/tour/apps.

20. Bomb Squad Shuts Down Disney Park Due To High-Tech GPS Scavenger Hunt http://www.fieldtechnologies.com/bomb-squad-shuts-down-disney-parkdue-to-high-tech-gps-scavenger-hunt.

21. Smartphone malware danger warning from experts. http://www.bbc.co.uk/ news/technology-15599264.

22. O'Donovan C, Hirsch E, Holohan E, McBride I, McManus R, Hussey J: Energy expended playing Xbox Kinect ${ }^{\mathrm{TM}}$ and $\mathrm{Wi}^{\mathrm{T}}{ }^{\mathrm{M}}$ games: a preliminary study comparing single and multiplayer modes. Physiotherapy 2012, 98(3):224-229. doi:10.1016/.jphysio.2012.05.010

23. Bandura A: Self-efficacy: the exercise of control. New York: W.H. Freeman; 1997.

24. Li F: The Exercise Motivation Scale: Its multifaceted structure and construct validity. Journal of Applied Sport Psychology 1999, 11:97-115.

25. Vallerand RJ, Losier GF: An integrative analysis of intrinsic and extrinsic motivation in sport. Journal of Applied Sport Psychology 1999, 11:142-169.
26. Nike + GPS Update Lets Runners Play a Game of Tag. http://mashable.com/ 2011/01/15/nike-plus-tag.

27. National Research Council and Institute of Medicine (ed.): Community programs to promote youth development. Washington: National Academy Press; 2002.

28. Game On: Challenge Grants Want Gamers To Go Outside. http://www. trueshare.com/DirectLink/FileAccess.aspx?DLID=S58DBX414uCj3h27xA26.

doi:10.1186/1476-072X-12-18

Cite this article as: Boulos and Yang: Exergames for health and fitness: the roles of GPS and geosocial apps. International Journal of Health Geographics 2013 12:18.

\section{Submit your next manuscript to BioMed Central and take full advantage of:}

- Convenient online submission

- Thorough peer review

- No space constraints or color figure charges

- Immediate publication on acceptance

- Inclusion in PubMed, CAS, Scopus and Google Scholar

- Research which is freely available for redistribution

Submit your manuscript at www.biomedcentral.com/submit
Ciomed Central 